\title{
IDENTIFICATION OF THE STEEL VISCOSITY AND DYNAMIC YIELD STRESS FOR THE NUMERICAL MODELLING OF CASTING SIMULATIONS IN THE SEMI-SOLID STATE
}

\begin{abstract}
Conditions of some casting processes cause flow of both liquid and semi-liquid metal alloys inside the die cavity. Generally, the continuous casting, squeeze casting or thixoforming could be classified as such processes. Design or optimisation of casting technology using numerical simulations requires knowledge of the rheological properties. The main objective of the experimental work, presented in this publication, is an analysis of the viscosity of 1.2080 (X210Cr12) high carbon steel in liquid and semisolid state. The secondary purpose of the experimental work was a development of the viscosity models used in continuous casting and thixoforming simulations. The significant achievement of this particular study was identification of thixotropy phenomenon which occurs not only during thixoforming, but also during magnetohydrodynamic stirring in continuous casting processes.

Keywords: continuous casting of steel, rheological properties, viscosity, thixoforming
\end{abstract}

\section{Introduction}

The most frequently used combination of processes in a contemporary steel plant is steelmaking followed by continuous casting [1]. The most important advantage of this route is the energy saving due to the obtaining of castings in the form of slabs. Thus, the expensive slabbing mill [2] is no longer needed. Thixoforming is another innovative method of processing metal alloys in the semi-solid state. This method has a lot of advantages compared to classic metal forming and foundry processes. Thixoforming techniques are based on modified devices typically used for forging or casting. This processing method is successfully applied in numerous industries which produce parts from aluminium and magnesium alloys [3-9]. Research is currently being conducted on the practical application of thixoforming in processing of high melting point metal alloys and numerical modeling of the continuous casting processes [10-12].

The rheological properties analysed in this work are very important for numerical simulations of casting processes. Such simulations are useful in the case of designing and optimisation of casting processes. Currently, quite a lot of commercial packages is accessible to simulate these technologies. In the most cases they are based on the one phase finite element method, while less frequently on the finite difference method. But, regardless of the used method such numerical models require the constitutive equations, describing the material rheology. In the case of liquid end semi-solid metal alloys, the viscosity models are normally used. Several types of such models can be considered, depending on factors influencing the material viscosity. The most important factors are: temperature, shear rate and time.

The main objective of this paper is to analyse the rheological properties of steel 1.2080 (X210Cr12) in the semi-solid state. It is a hot-work tool alloy steel, showing a high degree of hardness and toughness, and therefore its machining is very difficult. Thus products made of this steel are rather expensive. Therefore, thixoforming processes have recently been considered as an alternative technological route of production [13]. The experimental work was devoted to an analysis of both the viscosity and thixotropic properties of the steel. Thixotropy means the time-dependent fluid behaviour in which the apparent viscosity decreases over the time of shearing [14]. The viscosity of a fluid usually recovers to the initial value when shearing is stopped. The recovery process may take a long time. A rotational viscometer can be used to identify thixotropic behaviour due to the possibility of shearing of a sample at a constant rate over a very long time. However, the principal difficulty encountered during the experiments was the very high temperature of the semi-solid alloy. Therefore special equipment was required.

This paper is the tenth publication of a thematically related series in the process of conferment of a degree of doktor habilitowany (post-doc) on Dr. Krzysztof Sołek, pursuant to the rules laid down in the Act of 14 March 2003 on Academic Degrees and Titles and Degrees and Titles in the Arts, as amended (Law of the Republic of Poland). This series concerns the thixoforming of high melting point metal alloys. 


\section{Experimental procedure}

The viscosity measurement of analysed alloy was conducted using Searle's method [15-17] based on two concentric cylinders; rotating internal rod and stationary external cup (Fig. 1). A scheme of the viscometer is shown in Figure 2. It should be mentioned that turbulent flow can occur inside external cup while measuring of low-viscosity liquids at high rotational speeds. It can cause measuring inaccuracy and it is the reason of the optimisation of measurement tools shape. Within the confines of experimental work the high temperature viscometer FRS1600 designed by Anton Paar company was used. This viscometer is equipped with a furnace which allows the temperature range $400-1500^{\circ} \mathrm{C}$ to be achieved. The rheological analysis of steel 1.2080 in the liquid and semi-liquid states requires using the furnace in which the operating temperature is within the range $1150-1400^{\circ} \mathrm{C}$.
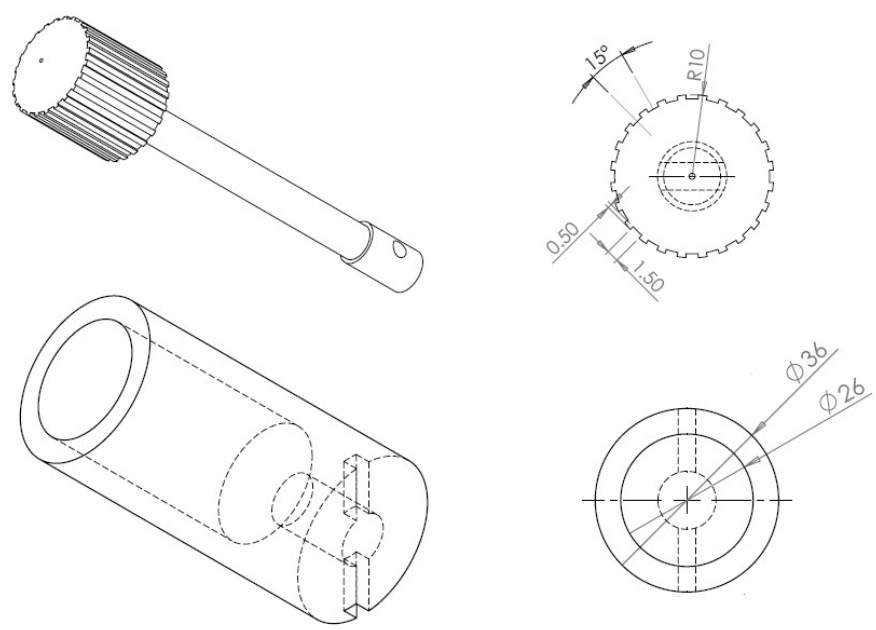

Fig. 1. Drawing of measurement tools (material - alumina) used in investigations

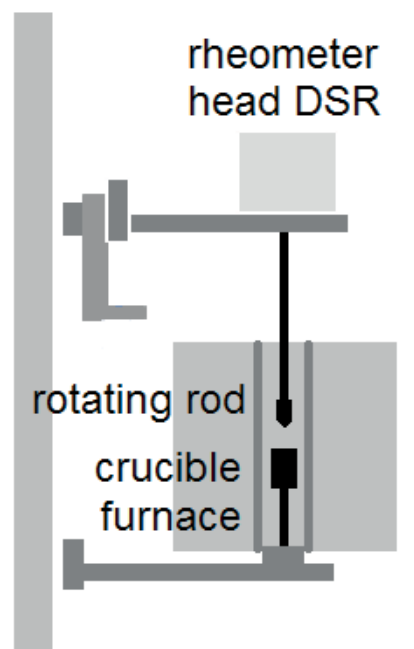

Fig. 2. Scheme of rotational viscometer used in investigations

The measurement of viscosity with the FRS 1600 viscometer is limited to a torque of about $200 \mathrm{mNm}$. In the measure- ments made in this study this limit was reduced to $150 \mathrm{mNm}$ for security reasons. The viscosity measurement was conducted with the help of a procedure incorporated in the software controlling the viscometer. First, a sample was heated to a temperature above the liquidus temperature. Next, the rotating rod was moved down into the crucible with the sample. Then, the measurement procedure could be run. A protective atmosphere was supplied to the furnace during the measurement in order to avoid oxidation of the liquid sample. The temperature of the sample could be accurately measured with a thermocouple located directly below the crucible. After the completion of the measurement, the sample was reheated to a temperature above the liquidus to remove the spindle from the crucible.

The chemical composition of the steel 1.2080 under investigation is shown in Table 1.

TABLE 1

Chemical composition of 1.2080 steel in weigth- $\%$

\begin{tabular}{|c|c|c|c|c|c|c|}
\hline \hline Element & $\mathbf{C}$ & $\mathbf{C r}$ & $\mathbf{M n}$ & $\mathbf{S i}$ & $\mathbf{M o}$ & $\mathbf{F e}-$ balance \\
\hline $\begin{array}{c}\text { Investigated } \\
\text { alloy }\end{array}$ & 2.09 & 11.9 & 0.29 & 0.27 & 0.26 & 84.7 \\
\hline
\end{tabular}

In the second stage of the experiment, the solid phase content of the investigated material was determined as a function of temperature in the solidification range. In order to do this, a high temperature DTA analysis had to be carried out. This analysis was conducted with an STA JUPITER 449 analyser produced by Netzsch. The DSCTGA heating curve and the liquid fraction distribution as a function of temperature for steel 1.2080 are shown in Figure 3. The measurements were carried out at a heating rate of 5 degrees per minute.

The diagram in Figure 3 shows the solidus and liquidus temperatures of approximately $1205^{\circ} \mathrm{C}$ and $1370^{\circ} \mathrm{C}$, respectively. Hence, the melting range of this alloy averages 165 degrees. This experiment allowed the temperature range suitable for the thixoforming process to be identified as between 1240 and $1340^{\circ} \mathrm{C}$

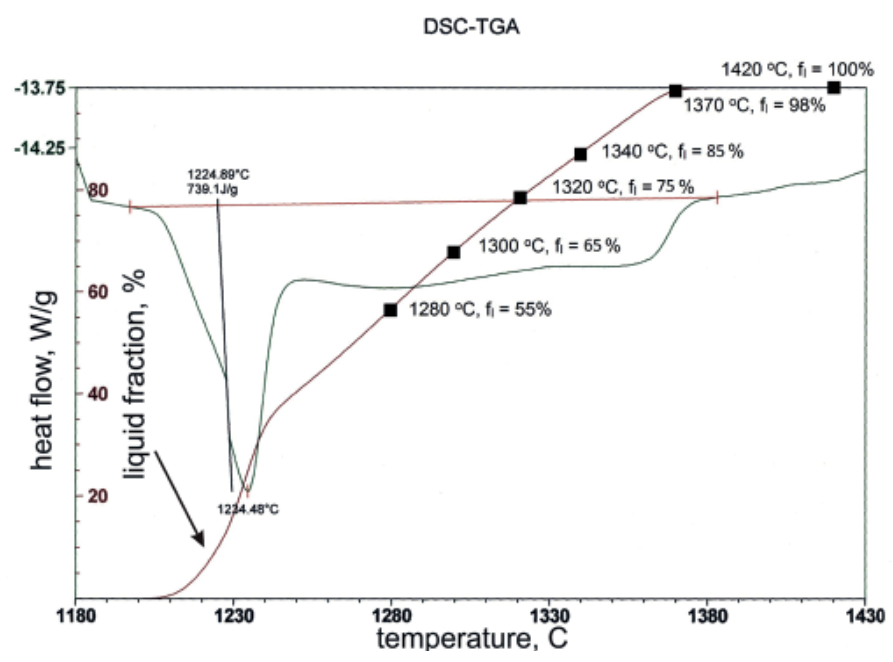

Fig. 3. Content of the solid phase in the 1.2080 alloy as a function of temperature $\left[{ }^{\circ} \mathrm{C}\right]$ 


\section{Viscosity of 1.2080 steel alloy}

The viscosity depend significantly on the amount of solid fraction in the material. The solid fraction is strongly correlated with the progress of the solidification process. Another factor influencing the viscosity is the shear rate (mech. the non-dilatational strain rate). Generally, a higher temperature and a higher shear rate reduce the material viscosity and improve its castability.

The first step of the measurement concerned the determination of the relationship between the alloy viscosity and temperature (Fig. 4). The general principle is that a temperature decrease causes an increase in the viscosity observed, especially for the semi-solid state of a metal alloy. The biggest viscosity increase appears at temperatures below $1300^{\circ} \mathrm{C}$. The results of the measurement can indicate the maximal temperature at which the initial shape of the sample can be maintained under the influence of the forces of gravity. This is related to the value of alloy viscosity above which the material loses its fluidity and the complete filling of the die without high pressure is not possible.

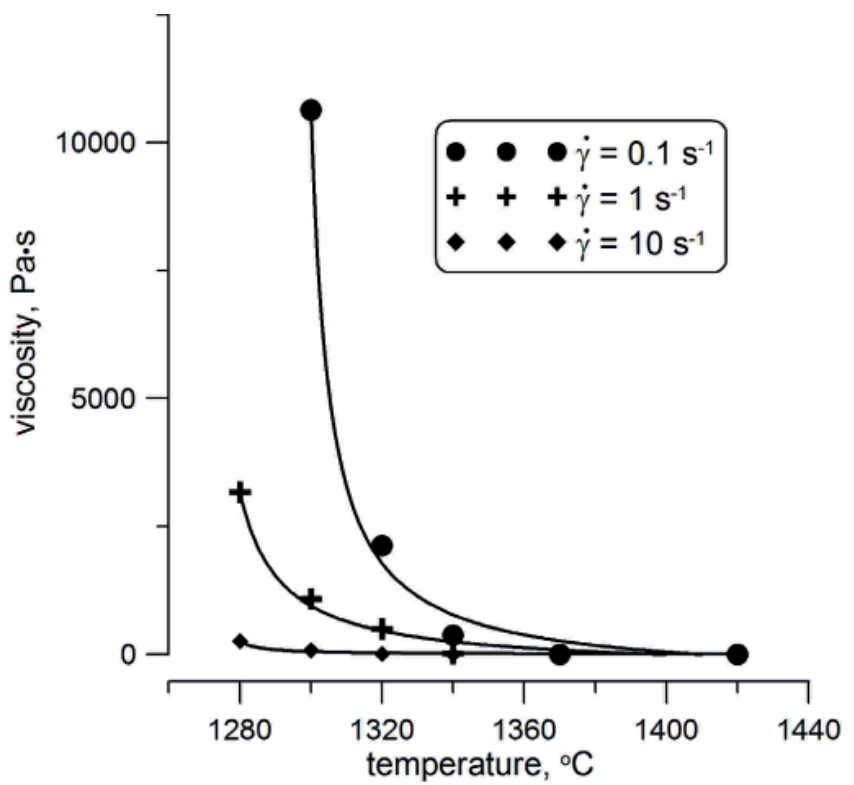

Fig. 4. Relationship between temperature and steel viscosity

An influence of the shear rate on the viscosity for selected temperatures is shown in Figure 5. The measurements of viscosity were executed at temperatures within the range $1280-1420^{\circ} \mathrm{C}$. The changes in viscosity were analysed within the range of the shear rate between 0.1 and $20 \mathrm{~s}^{-1}$.

The shape of the curves describing the relationship between viscosity and shear rate indicates the shear-thinning behaviour of the semi-solid steel slurry. This means that the viscosity decreases when the shear rate increases. The shearthinning behaviour is generally rarely seen in fully liquid metals, but is often observed in semi-solid alloys which are continuously cast or formed in thixoforming processes. Generally, the value of viscosity is strongly dependent on temperature and less dependent on the shear rate and morphology of the solid phase (state of microstructure). Finer and more disintegrated grains cause

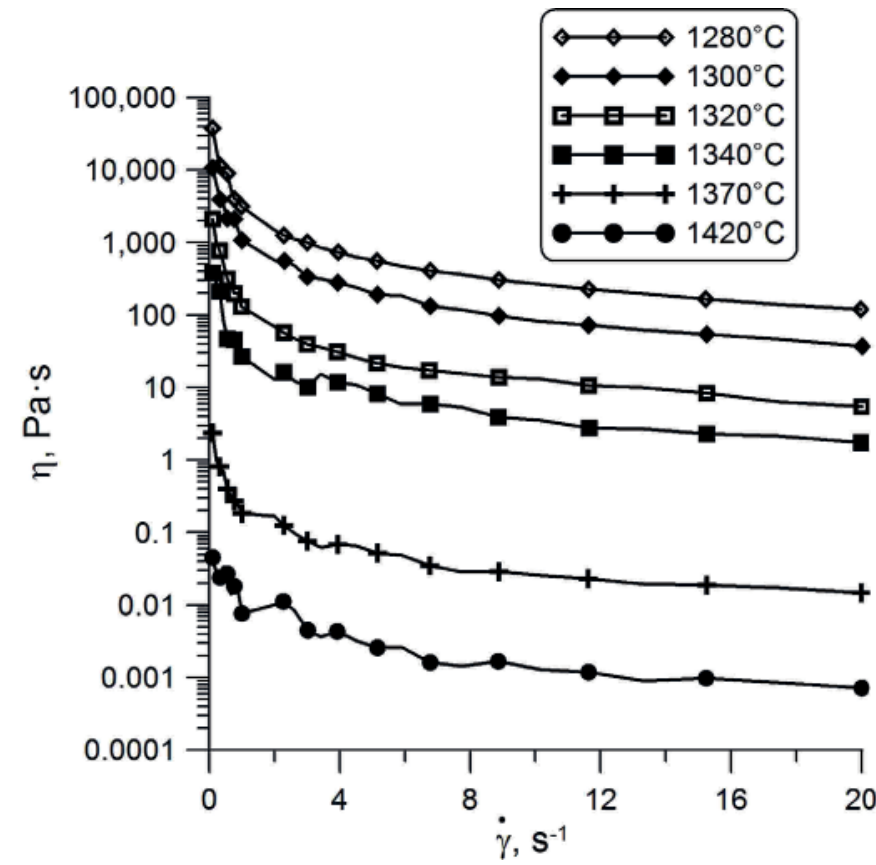

Fig. 5. Viscosity of analysed 1.2080 alloy versus shear rate for different temperatures

a decrease of the viscosity value. The state of the microstructure morphology results directly from the deformation history. Generally, the longer time and the higher rate of shearing cause the lower viscosity value.

\section{Yield stress and thixotropic properties of $\mathbf{1 . 2 0 8 0}$ steel alloy}

Figure 6 shows the changes in viscosity of the steel 1.2080 under investigation versus time for various shear rates. The general principle states that after an increase in the shear rate, viscosity decreases over time. This can be observed in Figure 6 .

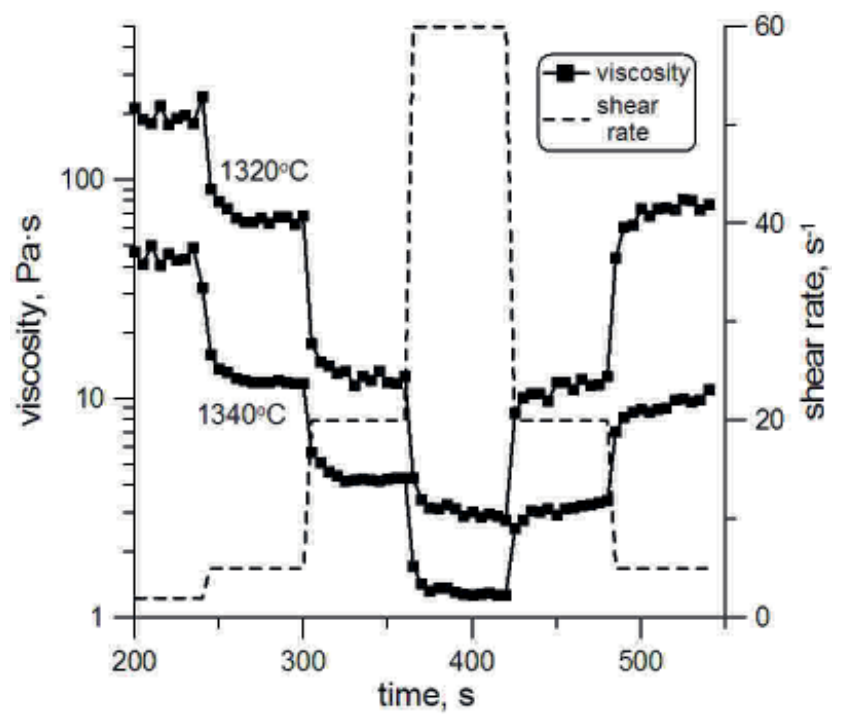

Fig. 6. Viscosity of analysed 1.2080 alloy versus time for different values of shear rate and temperature 
When the shear rate decreases, one can observe an increase in viscosity over time. Before the analysis of thixotropic properties, the semi-solid samples were sheared at a rate of approx. $5 \mathrm{~s}^{-1}$ for some time to obtain globular microstructures.

In the next stage of the experiments, the influence of resting time on the yield stress was analysed (Figs. 7-10). First, the samples were sheared for some time to obtain globular microstructures. Next, they were deformed over several cycles. In each cycle, the sample was subjected to a shear stress, and in each cycle this stress increased at a different rate. Generally, a lower rate of increase in shear stress caused a longer resting time and a higher yield stress (Figs. 7-8). These results mean that longer resting times cause a microstructure transformation allowing the solid skeleton to be rebuilt. The dots in Figures 7 and 8 associated with the shear rate correspond to the moment of the beginning of material flow. The value of shear stress recorded at this moment corresponds to the yield stress. A similar procedure was

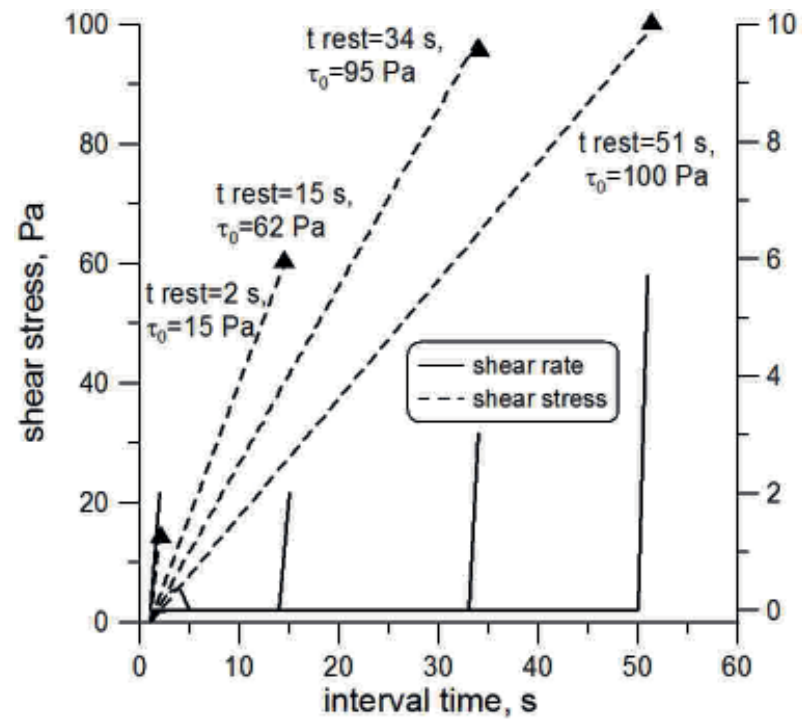

Fig. 7. Shear stress ramps obtained at $1360^{\circ} \mathrm{C}$

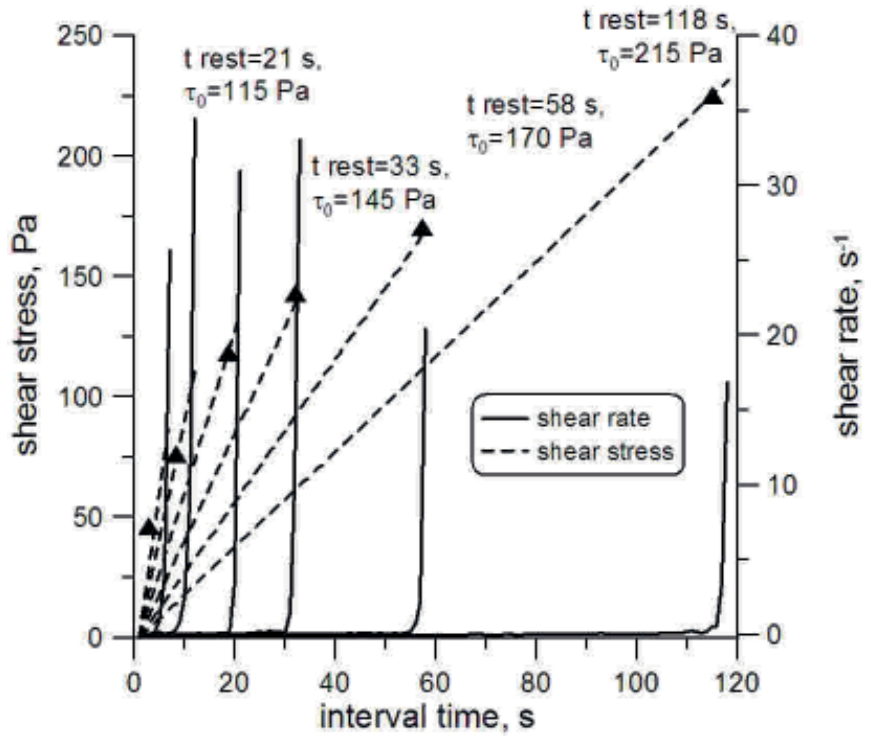

Fig. 8. Shear stress ramps obtained at $1340^{\circ} \mathrm{C}$ used in RWTH Aachen to investigate thixotropy in semisolid aluminium alloys [18]. In Figure 9 the flow stress curves for the 1.2080 steel for different resting times at $1340^{\circ} \mathrm{C}$ were shown. In this paper the values of yield stress were measured for two different temperatures 1340 and $1360^{\circ} \mathrm{C}$ (Fig. 10). A globular microstructure was obtained by applying shear rates of $10 \mathrm{~s}^{-1}$ to the alloy for half an hour before measurements.

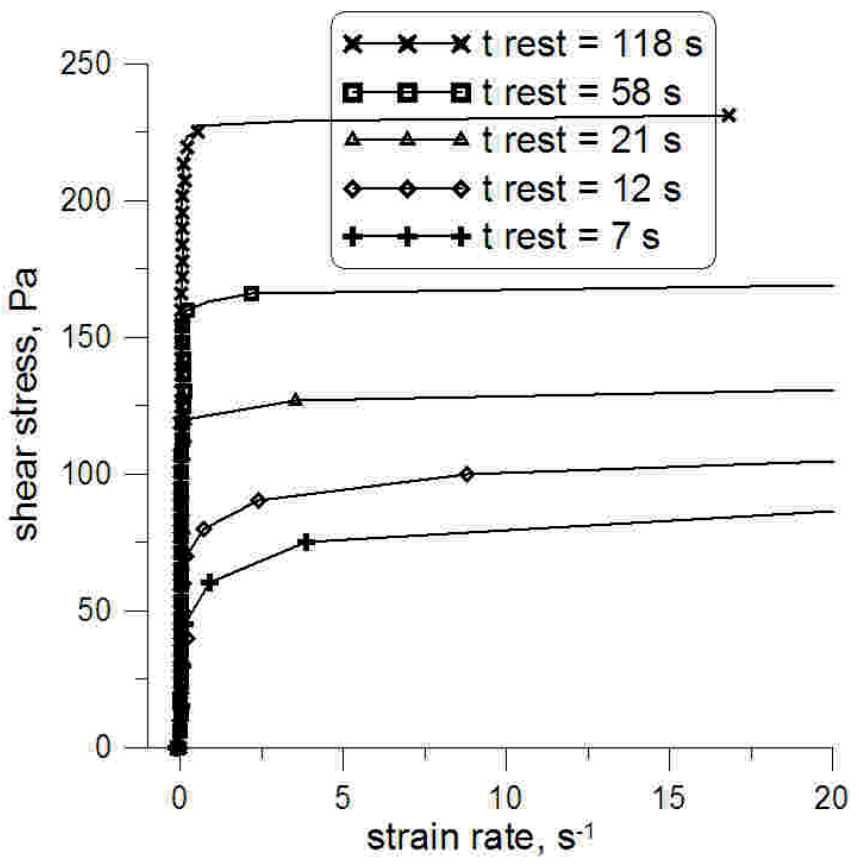

Fig. 9. Flow stress curves for 1.2080 steel for different resting times at $1340^{\circ} \mathrm{C}$ ("t rest" means resting time)

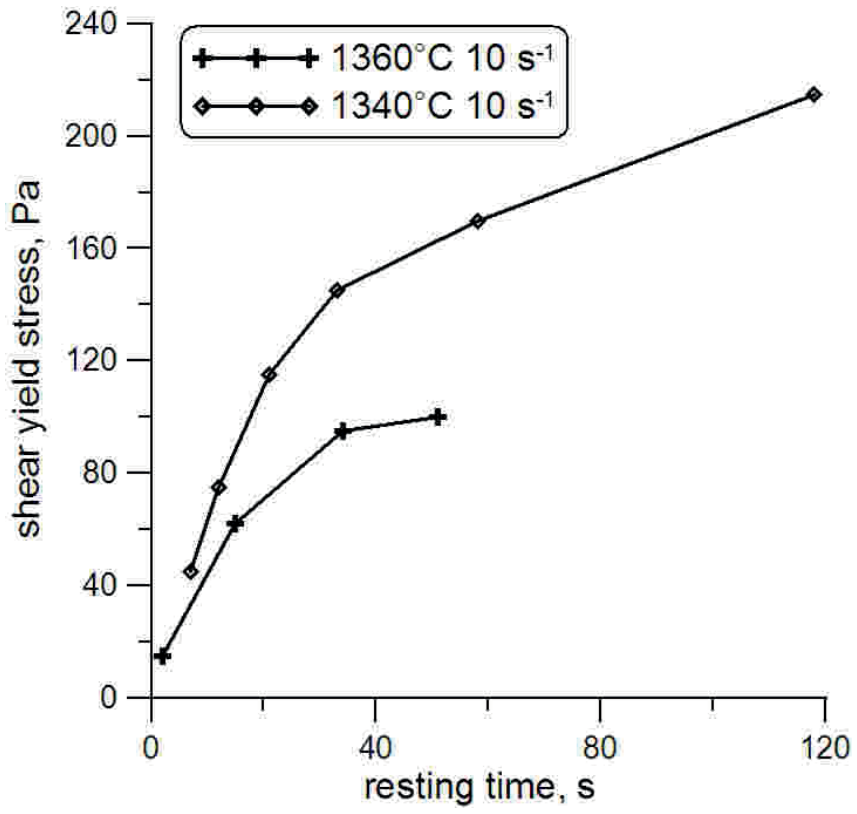

Fig. 10. Values of yield stress for 1.2080 steel versus resting time for samples at $1360^{\circ} \mathrm{C}$ and $1340^{\circ} \mathrm{C}$ previously sheared with rate of $10 \mathrm{~s}^{-1}$

The steel 1.2080 under investigation clearly shows the yield stress in the semi-solid state. The yield stress values strongly depend on the temperature and the resting time what can be 
observed in Figure 10. An influence of the resting time results directly from a dynamic nature of the yield stress. It means that with an increasing of the resting time an increasing of the dynamic yield stress value is observed. But its values change less and less with increasing of the resting time. When the resting time reaches the sufficiently long period the value of the yield stress becomes constant. This effect results from the thixotropic transition in the analysed alloy. A temperature is the second factor influencing on the yield stress. A decrease in temperature causes an increase in the yield stress value due to greater amount of the solid fraction in the metal alloy. Generally, it can be concluded that the yield point occurs in semi-solid steel alloys.

\section{Rheological models of $\mathbf{1 . 2 0 8 0}$ steel in the semi-solid state for ProCAST software}

The results of the viscosity measurements can be used in numerical simulations of continuous casting processes to determine the filling of the mould cavity. Such simulations can be executed by applying proper viscosity equations to numerical models. One of the viscosity models, used in ProCAST commercial casting packet, is expressed by Carreau-Yasuda equation:

$$
\eta=\eta_{\infty}+\left(\eta_{0}-\eta_{\infty}\right) \cdot\left[1+(\lambda \cdot \dot{\gamma})^{\alpha}\right]^{\frac{n-1}{\alpha}}
$$

where:

$\dot{\gamma}$ - shear rate,

$h_{0}-$ zero strain rate viscosity,

$\eta_{\infty}-$ infinite strain rate viscosity,

$\lambda$ - phase shift,

$n$ - power law coefficient,

$\alpha$ - Yasuda coefficient.

The parameters values of the Carreau-Yasuda model for 1.2080 steel are shown in Fig. 11. The approximation was carried out using the least squares method implemented in the Rheoplus software supplied by Anton Paar. The parameters values obtained depend on temperature and can directly be applied in the software to be used in numerical simulations of the shaping process.

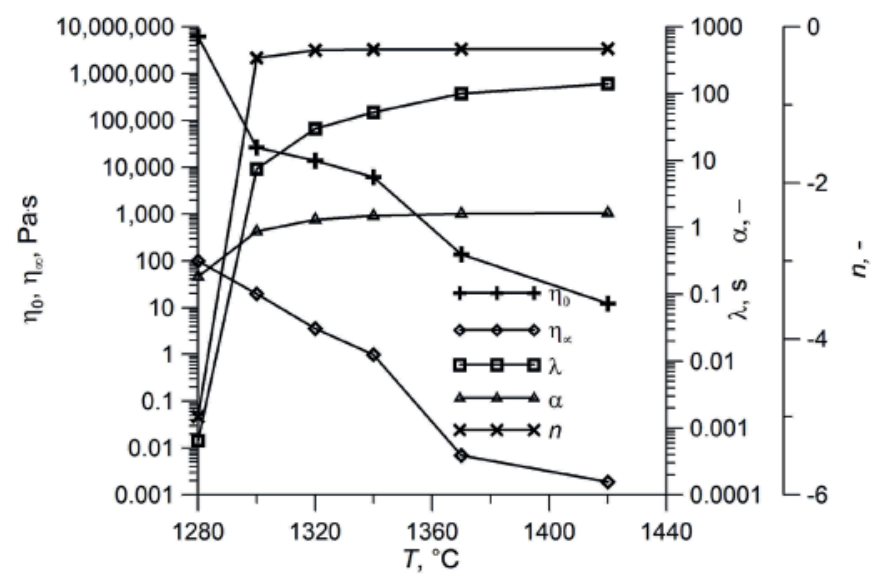

Fig. 11. Parameters values of the Carreau-Yasuda model for 1.2080 steel versus temperature
In the case of thixoforming processes simulations using of the Power Law Cut-Off equation [19] is more preferable:

$$
\begin{aligned}
& \eta=\eta_{0} \cdot(K \cdot \dot{\gamma})^{n} \quad \dot{\gamma} \geq \dot{\gamma}_{0} \\
& \eta=\eta_{0} \cdot\left(K \cdot \dot{\gamma}_{0}\right)^{n} \quad \dot{\gamma}<\dot{\gamma}_{0}
\end{aligned}
$$

where:

$\dot{\gamma}-$ shear rate,

$\dot{\gamma}_{0}$ - the critical "cut-off" value of the shear rate,

$h_{0}-$ zero shear rate viscosity,

$K-K$-Factor,

$n$ - power law coefficient.

The PLCO equation allows to simulate thixotropy phenomenon to a limited extend only. The critical ("cut-off") shear rate value is responsible for elimination of the viscosity increase with decreasing of the shear rate. This approach is suitable for dynamic thixoforming processes in which the rebuilding of the solid skeleton in the alloy structure rather is impossible. However, the PLCO model fully takes into consideration the shear thinning phenomenon. It is especially important in the case strongly viscous alloys, such as 1.2080 steel in semi-liquid and liquid state. This behaviour is confirmed by high negative values of the power low coefficient " $n$ " at all investigated temperatures. The estimated parameters values of the PLCO model for 1.2080 steel are shown in Figure 12. The approximation was carried out using the least squares method. The values of $K$-Factor was assumed to $1 \mathrm{~s}$ in this work. The correctness of viscosity approximation versus the shear rate is presented on Figure 13.

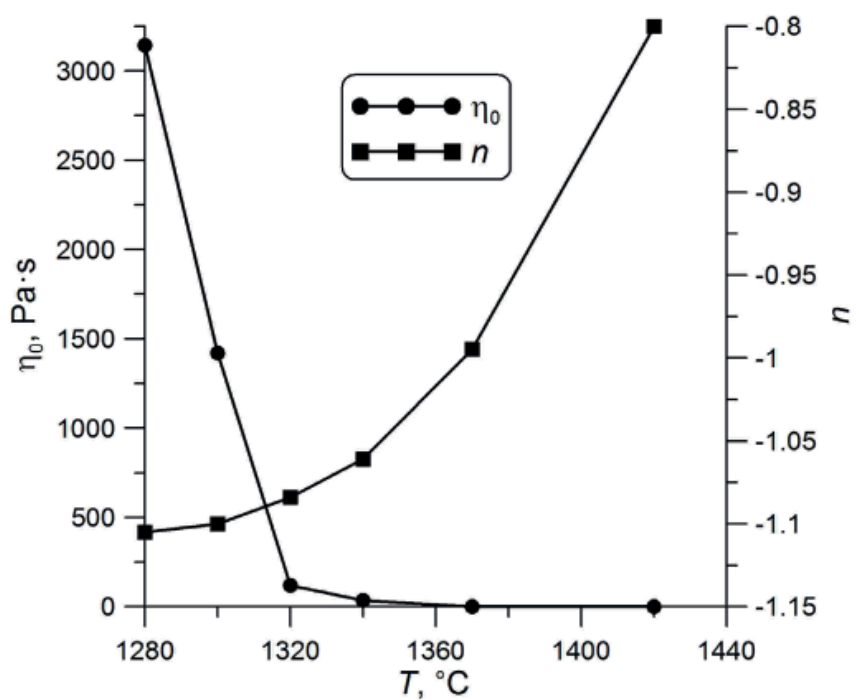

Fig. 12. Values of zero strain rate viscosity and power law coefficient for 1.2080 steel versus temperature

\section{Conclusions}

In this work several scientific achievements were obtained. First of all the 1.2080 steel viscosity in liquid and semi-solid state was analysed. Additionally, the Carreau-Yasuda and the Power Law Cut-Off models describing the alloy viscosity were 


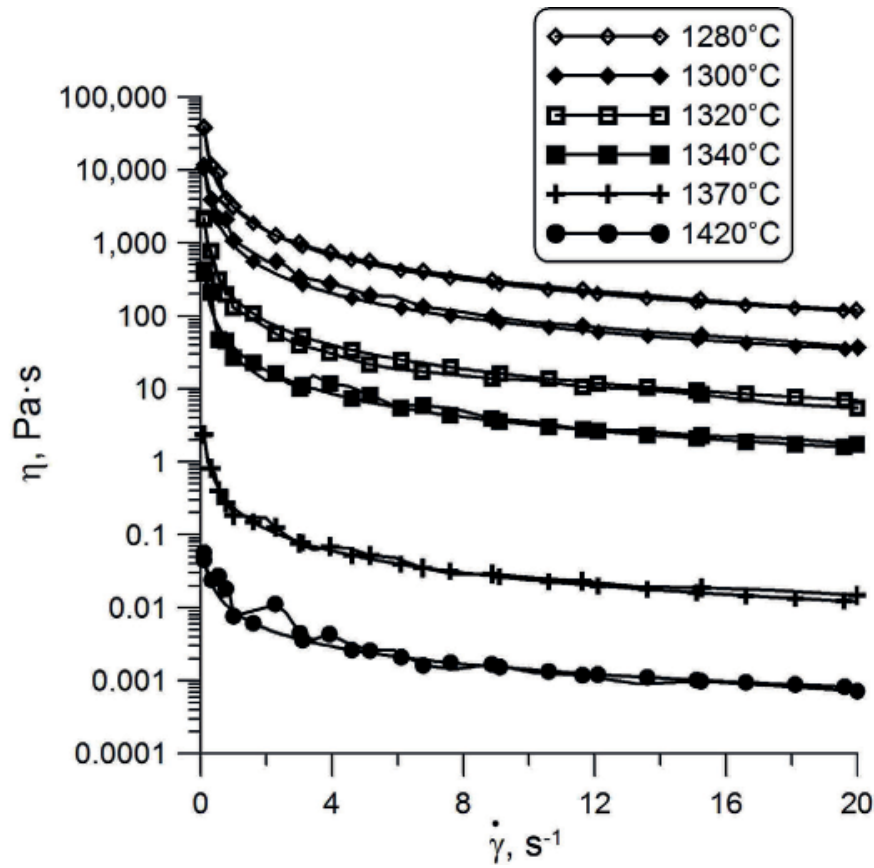

Fig. 13. The curves which approximate (using PLCO model) recorded values of viscosity versus the shear rate

developed. Such data are necessary in the numerical modelling of casting processes. An access to them from the literature is very limited. Also thermodynamic calculations do not give proper results.

Knowledge of steel viscosity allows to predict correctly flow profile inside the casting moulds. In the case of the continuous casting processes the correct profile of the solid skin, both inside and below the mould will be able to determined. However, in the case of thixoforming, knowledge of viscosity is necessary in order to determine correctly the dies forces.

The second scientific achievement concerns identification of steel behaviour in the liquid and semi-liquid state. The shear thinning behaviour was observed. It means that the steel viscosity depends not only on temperature but also on the shear rate. Especially, it is significant in the case of processes where the shear rate distribution is non-uniform. Such behaviour occurs in the case of both continuous casting and thixoforming processes.

\section{Acknowledgement}

Research financed through statutory funds of AGH University of Science and Technology in Krakow, no. 11.11.110.225.

\section{REFERENCES}

[1] http://www.ceicdata.com/en/blog/ceic-database-expansionworldsteel-crude-steel-production-and-continuously-caststeel- output

[2] V.E. Zelenskii, V.A., Klimenko, E.E. Beigel'zimer, A.A. Budakva, Steel Transl. 27 (2), 27-33 (1997).

[3] U.A. Curle, J.D. Wilkins, G. Govender, Solid State Phenom. 192-193, 225-230 (2013). DOI: 10.4028/www.scientific.net/ SSP.192-193.225

[4] P. Kapranos, La Metallurgia Italiana. 7-8, $25-29$ (2012).

[5] G. Vaneetveld, A. Rassili, J. -C. Pierret, J. Lecomte-Beckers, Solid State Phenom. 141-143, 707-712 (2008).

[6] K. Solek, A. Bialobrzeski, Arch. Metall. Mater. 49 (3), 681- 698 (2004).

[7] D. Walukas, S. LeBeau, N. Prewitt, R. Decker, in: Proc. 6th Int. Conf. on Semi-Solid Processing of Alloys and Composites, G.L. Chiarmetta, M. Rosso (Ed.), Edimet Spa, Brescia - Italy 2000.

[8] D. Weiss, M. Black, Solid State Phenom. 72, 192-193 (2013). DOI: 10.4028/www.scientific.net/SSP.192-193.72

[9] K. Young, P. Eisen, in: Proc. 6th Int. Conf. on Semi-Solid Processing of Alloys and Composites, G.L. Chiarmetta, M. Rosso (Ed.), Edimet Spa, Brescia - Italy 2000.

[10] H.V. Atkinson, A. Rassili, Int. J. Mater., Form. 3, 791-795 (2010). DOI: $10.1007 / \mathrm{s} 12289-010-0889-7$.

[11] J. Dutkiewicz, L. Rogal, K. Solek, A. Mitura, Int. J. Mater. Form. 2, 753-756 (2009). DOI: 10.1007/s12289-009-0558-x

[12] K. Solek, L. Trębacz, Arch. Metall. Mater. 57, 355 (2012).

[13] B. Masek, D. Aisman, M. Behulova, H. Jirkova, T. Nonferr. Metal. Soc. 20 (Supplement: 3), S1037-S1041 (2010).

[14] H.A. Barnes, Thixotropy - a review, J. Non-Newtonian Fluid Mech., 70, 1-33 (1997). DOI: 10.1016/S0377-0257(97)00004-9.

[15] M. Dziubiński, T. Kiljański, J. Sęk, Podstawy reologii i reometrii płynów, 2009 Wydawnictwo Politechniki Łódzkiej, Łódź.

[16] T. Kiljański, M. Dziubański, J. Sęk, K. Antosik, Wykorzystanie pomiarów właściwości reologicznych płynów w praktyce inżynierskiej, 2009 Wydawnictwo EKMA Krzysztof Antosik, Warszawa.

[17] G.T. Mezger, The Rheology Handbook: For users of rotational and oscillatory rheometers, 2006 Vincentz Network, Hannover.

[18] A. Moll, M. Modigell, Int. J. Mater. Form. 3, 779-782 (2010). DOI: $10.1007 / \mathrm{s} 12289-010-0886-x$

[19] [I. Orgeas, J.P. Gabathuler, T.H. Imwinkelried, Ch. Paradies, M. Rappaz, Modelling Simul. Mater. Sci. Eng. 11 (4), 553-574 (2003). 